\title{
Combined effects of goethite nanoparticles with metallic contaminants and an organophosphorus pesticide on Eisenia andrei
}

\author{
Marcela I. Cáceres-Wenzel ${ }^{1} \cdot$ Julio S. Fuchs ${ }^{1,2} \cdot$ Florencia N. Bernassani $^{1} \cdot$ Adriana C. Cochón $^{1}$ \\ Received: 25 September 2019 / Accepted: 23 March 2020 \\ (C) Springer-Verlag GmbH Germany, part of Springer Nature 2020
}

\begin{abstract}
The effects of mixtures of nanoparticles (NPs) and other chemicals have been poorly studied in terrestrial invertebrates. In this study, we investigated the effects of binary mixtures of goethite $(\alpha-\mathrm{FeOOH}) \mathrm{NPs}$ and metallic $(\mathrm{Cd}$ and $\mathrm{Pb})$ or organic (chlorpyrifos, CPF) contaminants in Eisenia andrei earthworms. We used the filter paper contact test to evaluate (i) the uptake of NPs in organisms exposed to the mixtures of NPs+Metals and NPs+CPF and (ii) the potential effects of the mixture of NPs+CPF on the CPF-induced inhibition of the biomarker enzymes acetylcholinesterase (AChE) and carboxylesterases (CES). We used the artificial soil test to deepen the study on joint effects of NPs+CPF. All compounds were applied separately and in binary mixtures. In the single exposure treatment, Fe levels decreased significantly in organisms exposed to NPs on filter paper, suggesting systemic effects aimed at eliminating Fe incorporated through NPs. Conversely, earthworms exposed to binary mixtures showed Fe levels similar (NPs+Metals) to or higher (NPs+CPF) than controls. The earthworms single exposed to NPs presented no changes in AChE and CES activities. In the artificial soil test, the only treatment that showed AChE inhibition after $72 \mathrm{~h}$ was single CPF exposure, while no significant changes were observed in CES activity. However, after 7-day exposure in artificial soil or 72-h exposure on filter paper, the mixture of NPS+CPF induced a similar degree of AChE and CES inhibition as single CPF exposure. All these suggested that NPs did not produce neurotoxic effects, and that the inhibition of the enzymes' activities in all cases was due to the presence of the pesticide. On the other hand, the differences in the pattern of Fe accumulation in the earthworms indicate that the presence of other contaminants in the exposure media can modify the uptake and/or the excretion of Fe and evidence the interactions that may be found in binary mixtures of metal oxide NPs and other pre-existing contaminants in the soil ecosystem.
\end{abstract}

Keywords Eisenia andrei $\cdot$ Goethite $\cdot$ Nanoparticles $\cdot$ Cadmium $\cdot$ Lead $\cdot$ Chlorpyrifos

\section{Introduction}

Nanotechnology has recently grown to become a multi-billion dollar industry with over 3000 registered consumer products

Responsible editor: Chris Lowe

Adriana C. Cochón

adcris@qb.fcen.uba.ar

1 Departamento de Química Biológica, Facultad de Ciencias Exactas y Naturales, Universidad de Buenos Aires, Ciudad Universitaria, Pab. II. 4to piso, 1428 Buenos Aires, Argentina

2 Instituto de Química Biológica de la Facultad de Ciencias Exactas y Naturales (IQUIBICEN), CONICET-Universidad de Buenos Aires, Buenos Aires, Argentina containing nanoparticles (NPs) (DTU Environment 2018). The remarkable versatility of these particles is reflected, among others, in their use in the development of selfcleaning glasses, antimicrobial patches, and therapeutic agents for the treatment of various pathologies (Dowling 2004; Sanvicens and Marco 2008; Missaoui et al. 2018). Moreover, potential applications of NPs for remediation processes of contaminated water and soil are being investigated (Wu et al. 2019). In particular, iron oxides and oxyhydroxides engineered NPs, such as goethite, are a promising material, for example, in catalysis, sensors, and also in remediation processes (Cross et al. 2010; Chernyshova et al. 2011; Parveen et al. 2012; Hjorth et al. 2017; Nanorem 2017).

NPs can enter the environment not only through production or application processes but also through waste management 
disposal and outdoor aging products. For example, paints containing nano-Ag that were exposed to ambient outdoor weather for 1 year showed strong leaching of NPs during initial runoff events (Kaegi et al. 2010). Upon release and emission, they can interact with numerous pre-existing contaminants, such as pesticides and heavy metals. These interactions are enhanced by the high surface area of NPs and can alter the bioavailability and potential toxic effects of contaminants (Pachapur et al. 2016).

Unlike other contaminants, metals cannot be degraded. They concentrate in water, soil, and sediments and/or accumulate in living organisms (Vijver et al. 2003). Due to intense industrialization and urbanization, the release of contaminants such as heavy metals continues to rise. Among them, cadmium $(\mathrm{Cd})$ and lead $(\mathrm{Pb})$ have become widespread in the environment because of human activities (Alloway 2013). Cd has the ability to bioaccumulate in tissues at high concentrations and can be biomagnified through the trophic chain. Anthropogenic $\mathrm{Cd}$ sources include, for example, Ni-Cd batteries, plastics, and also from the application of soil fertilizers based on phosphates that are contaminated with this metal (Roberts 2014; Wu et al. 2016). Anthropogenic Pb comes mostly from mining, smelting of ore, fossil fuels, manufacture, and use of $\mathrm{Pb}$-containing products (ATSDR 2019).

Chlorpyrifos (CPF) is a broad-spectrum organophosphorus (OP) non-systemic insecticide and acaricide, used to control crop pests worldwide (Jänsch et al. 2006). The mode of action of CPF is through acetylcholinesterase (AChE) inhibition at the synaptic junction. This leads to alterations in the normal functioning of the nervous system and eventually death. In addition, carboxylesterases (CES) are a family of enzymes that catalyze the hydrolysis of carboxylic esters by the addition of water (Wheelock et al. 2005). Like cholinesterases (ChEs), CES are B-esterases because they are inhibited by OPs (Aldridge 1953); hence, they are also used in environmental studies of exposure to OP pesticides. The combined monitoring of CES and $\mathrm{AChE}$ activities can provide more useful information on exposure to OPs than the measurement of AChE alone in many aquatic and terrestrial species (Wheelock et al. 2005; Cacciatore et al. 2013).

Among soil organisms, earthworms are highly appropriate terrestrial model organisms for toxicity tests, as they play a vital role in decomposition, nutrient cycles, and the development and maintenance of soil structure. Particularly, Eisenia andrei is widely used as a standard organism to evaluate soil quality because of its low cost, easy handling, and the standardization of acute and subchronic toxicological tests (OECD 1984; Gong and Perkins 2016).

Recently, we have shown that dermal exposure of $E$. andrei to mixtures of goethite $(\alpha-\mathrm{FeOOH}) \mathrm{NPs}$ and $\mathrm{Cd}$ or $\mathrm{Pb}$ reduced the bioavailability of these metals (Cáceres Wenzel et al. 2016). Therefore, testing for joint effects of mixtures is crucial as it may show different toxicity patterns compared with the single chemical, and in the environment, pesticides and metals are likely to co-exist in most agricultural soil ecosystems (Wang et al. 2015). In this study, we wanted to investigate the effects of binary mixtures of goethite NPs with metallic $(\mathrm{Cd}$ and $\mathrm{Pb})$ or organic $(\mathrm{CPF})$ contaminants on Fe accumulation in $E$. andrei. We then evaluated the potential effects of the binary mixture of NPs and CPF on the OP-induced inhibition of $\mathrm{AChE}$ and CES.

\section{Materials and methods}

\section{Chemicals}

Goethite NPs (product number 720704, Sigma-Aldrich, Argentina) were provided as a water suspension $(20 \% \mathrm{w} / \mathrm{w})$. According to the manufacturer, nominal range of particle size was less than $100 \mathrm{~nm}$. NP suspensions for bioassays were prepared by sonicating the stock suspension for $30 \mathrm{~min}$ followed by dilution in distilled water.

The following compounds: Chlorpyrifos (CPF, PESTANAL $® 99.9 \%$ purity), 5,5' dithiobis-2 nitrobenzoic acid (DTNB), acetylthiocholine iodide (AcSChI), pnitrophenyl butyrate, and bovine serum albumin (BSA) were purchased from Sigma-Aldrich (Argentina). $\mathrm{CdCl}_{2} \cdot 2 \frac{1}{2} \mathrm{H}_{2} \mathrm{O}$ was purchased from $\mathrm{M} \& \mathrm{~B}$ Laboratory Chemicals and $\mathrm{Pb}\left(\mathrm{NO}_{3}\right)_{2}$ from Mallinckrodt. All other reagents were of analytical grade.

\section{Goethite NP characterization}

The morphology of goethite NPs was analyzed by scanning electron microscopy (SEM) using a Carl Zeiss model NTSSupra 40, Germany (Centro de Microscopía Avanzada, Facultad de Ciencias Exactas y Naturales, Universidad de Buenos Aires). SEM specimens were prepared by dropcasting one or two drops of NPs solution $(10 \mathrm{mg} / \mathrm{L})$ onto carbon-coated copper grids and allowing to dry at room temperature overnight. The SEM technique was combined with Energy Dispersive Spectroscopy (EDS) to obtain composition measurements.

\section{Organisms selected}

E. andrei (Oligochaeta, Lumbricidae) were obtained from the culture stocks maintained in our laboratory since 1997. Longterm use of isolated laboratory cultures may lead to production of individuals adapted to laboratory conditions and/or inbreeding (Lowe and Butt 2007). To increase genetic variation in our culture stocks, we periodically introduced individuals coming from other research institutions. In addition, our population was kept in 10-12 40-L plastic containers, but individuals from each of them were regularly exchanged to promote 
random reproduction. Prior to the bioassays, earthworms were randomly removed from these containers, rinsed with tap water, and stored on damp filter paper for $24 \mathrm{~h}$ (in the dark at $22{ }^{\circ} \mathrm{C}$ ) to void the gut contents. The earthworms used in the assays were all adults with well-developed clitellae $(0.30$ $0.50 \mathrm{~g}$ after voiding the gut content).

\section{Bioassays using the filter paper contact toxicity method}

Earthworms were either single exposed $(72 \mathrm{~h}$ ) to filter papers (Whatman No. 1, surface $=60 \mathrm{~cm}^{2}$ ) impregnated with NPs, $\mathrm{Cd}, \mathrm{Pb}$, and $\mathrm{CPF}$, or to the mixture of $\mathrm{NPs}+\mathrm{Cd}, \mathrm{NPs}+\mathrm{Pb}$, and $\mathrm{NPs}+\mathrm{CPF}$ following the OECD guidelines (OECD 1984) with modifications (the filter papers were dried outside the vial instead of inside).

Preliminary experiments were carried out in order to choose the concentration of $\mathrm{Cd}, \mathrm{Pb}$, and $\mathrm{CPF}$ to be used in the assays, so as to allow an appropriate evaluation of the effects of the mixtures. Thus, prior to the binary mixture assays, earthworms were exposed to different $\mathrm{Cd}$ concentrations $\left(0-16.6 \mu \mathrm{g} \mathrm{Cd} / \mathrm{cm}^{2}\right)$ for $72 \mathrm{~h}$. One hundred percent mortality was observed at the highest concentration tested, while at the other concentrations, no mortality was recorded. An appreciable accumulation of this metal was observed at the lowest concentration $\left(0.4 \mu \mathrm{g} \mathrm{Cd} / \mathrm{cm}^{2}\right)$, so it was selected for further studies. For comparative purposes, an equimolar $\mathrm{Pb}$ concentration $\left(0.214 \mathrm{mM}\right.$, equivalent to $\left.0.74 \mu \mathrm{g} \mathrm{Pb} / \mathrm{cm}^{2}\right)$ was used. At this level of $\mathrm{Pb}$, no mortality was observed.

In the case of $\mathrm{CPF}$, earthworms were first exposed to varying concentrations of the pesticide dissolved in acetone $(0$ $1 \mu \mathrm{g} / \mathrm{cm}^{2}$ ) for $72 \mathrm{~h}$ in order to choose a concentration that would inhibit $40-50 \%$ the activity of AChE enzyme. A halfmaximal effective concentration $\left(\mathrm{EC}_{50}\right)$ of $0.81 \pm 0.02 \mu \mathrm{g} / \mathrm{cm}^{2}$ was determined with OriginPro 9.0 software (OriginLab, Northampton, MA). Therefore, a CPF concentration of $0.75 \mu \mathrm{g} / \mathrm{cm}^{2}$ was selected for further studies.

For the assays involving NPs, filter papers were impregnated with $1 \mathrm{~mL}$ of an aqueous suspension of $3 \mathrm{~g} \mathrm{NPs} / \mathrm{L}$ (final concentration, $50 \mu \mathrm{g} \mathrm{NPs} / \mathrm{cm}^{2}$ ). This is in line with concentrations recently reported for remediation processes $(5 \mathrm{~g} / \mathrm{L})$ (Nanorem 2017). In the case of the assays involving mixtures of NPs and metals, after drying the NP-impregnated papers in a fume hood, flat-bottom vials were lined with the papers and $1 \mathrm{~mL}$ of equimolar solutions of $\mathrm{Cd}$ or $\mathrm{Pb}$ was pipetted into each vial while rotating it horizontally to impregnate the papers in a homogeneous way (final metal concentrations, $0.40 \mu \mathrm{g} \mathrm{Cd} / \mathrm{cm}^{2}$ or $0.74 \mu \mathrm{g} \mathrm{Pb} / \mathrm{cm}^{2}$ ). Solvent control vials contained filter papers impregnated only with water.

In the case of the studies involving mixtures of NPs and $\mathrm{CPF}\left(50 \mu \mathrm{g} \mathrm{NPs} / \mathrm{cm}^{2}+0.75 \mu \mathrm{g} \mathrm{CPF} / \mathrm{cm}^{2}\right)$, filter papers were first impregnated with $1 \mathrm{~mL}$ of aqueous medium (water or NPs suspension in distilled water). Then, $1 \mathrm{~mL}$ of organic solvents (acetone or CPF solution prepared in acetone) was added according to the different treatments. Papers were dried in the fume hood, and then $1 \mathrm{~mL}$ of distilled water was added to each vial to moisten the filter paper. Solvent controls followed the same treatment, i.e., papers were first impregnated with $1 \mathrm{~mL}$ of distilled water, then with $1 \mathrm{~mL}$ of acetone. They were later dried and moistened with $1 \mathrm{~mL}$ of distilled water.

In all cases, one worm per vial was added, and 6 earthworms for each treatment were prepared for all experiments. After addition of earthworms, each vial was covered with a piece of nylon stockings and closed with a cap with a ventilation hole (cap diameter $25 \mathrm{~mm} /$ hole diameter $15 \mathrm{~mm}$ ) and placed in the dark at $22 \pm 2{ }^{\circ} \mathrm{C}$. At the end of the exposure period, earthworms were rinsed with distilled water. Those destined to atomic absorption spectroscopy (AAS) determinations were used immediately as described below. Organisms used for enzyme determinations were stored at $-80^{\circ} \mathrm{C}$ until use.

\section{Bioassays using artificial soil}

Earthworms were exposed to artificial soil spiked with NPs, $\mathrm{CPF}$, and the mixture of NPs and CPF following the OECD guidelines (OECD 1984) with slight modifications (the test duration was modified to $72 \mathrm{~h}$ and 7 days instead of 7 and 14 days). The artificial soil used consisted of $10 \%$ ground sphagnum peat $(<0.5 \mathrm{~mm}), 20 \%$ kaolinite clay $(>50 \%$ kaolinite), and $70 \%$ fine sand with more than $50 \%$ of the particles between 50 and $200 \mu \mathrm{m}$. A small amount of calcium carbonate was added to adjust the $\mathrm{pH}$ to $6.0 \pm 0.5$. The NP application concentration was based on our previous studies (Cáceres Wenzel et al. 2016). CPF concentration was selected after exposing earthworms to varying concentrations $(0-87 \mathrm{mg} / \mathrm{kg})$ of the pesticide in soil for 7 days in order to choose a concentration that would inhibit $50 \%\left(\mathrm{EC}_{50}\right)$ activity of $\mathrm{AChE}$ enzyme. This study was carried out using either pure CPF (99.9\%) or a commercial formulation of CPF (TERMINATOR CIAGRO®, Ciagro S.A., Argentina). No significant differences were found between Pure-CPF or Formulated-CPF (results not shown). Therefore, and to simulate crop field conditions, the commercial formulation of $\mathrm{CPF}$ was used for soil studies. The concentration selected was $18 \mathrm{mg} / \mathrm{kg}$, based on the $\mathrm{EC}_{50}$ value for AChE inhibition.

The soil for the CPF treatments (single and mixture exposure) was prepared $24 \mathrm{~h}$ before starting the experiment. CPF was added to artificial dry soil as an acetone solution to obtain a final concentration of $18 \mathrm{mg} / \mathrm{kg}$ of dry soil, gently mixed and left for $24 \mathrm{~h}$ in a fume hood to let acetone evaporate. For the control treatment, the same amount of acetone as in CPF single treatment was added. For NP single exposure, an appropriate amount of an aqueous suspension of goethite NPs (to $75 \%$ of the soil water holding capacity, WHC) was mixed with 
soil to obtain a concentration of $100 \mathrm{mg} \mathrm{NPs} / \mathrm{kg}$ of dry soil. The soil destined to the binary mixture exposure, which was previously treated with $\mathrm{CPF}$, was mixed with the same NP suspension as mentioned above. Distilled water was added to CPF and control treatments to reach the same WHC. Each treated soil was divided into three equal parts and placed inside plastic containers (120-mm diameter/70-mm height). Six worms were placed in each container covered with perforated plastic film to prevent moisture loss and allow exchange of air. The containers were stored at $20 \pm 2{ }^{\circ} \mathrm{C}$ under photoperiod of 16-h light/8-h dark. Single earthworms were removed from soil after $72 \mathrm{~h}$ and 7 days of treatment and transferred to individually marked plastic Petri dishes with moist paper filter to void the content of their guts ( $24 \mathrm{~h}$, in the dark) and later stored at $-80{ }^{\circ} \mathrm{C}$ until use in enzymatic determinations.

\section{Fe accumulation in earthworms}

To determine the uptake of $\mathrm{Fe}$, the total metal concentration of sampled individuals from the filter paper contact test was quantified by AAS after a digestion process (Cáceres Wenzel et al. 2016). Optimal digestion conditions for the quantification of Fe levels in tissues were determined using untreated organisms spiked with a known concentration of NPs. The digestion process was performed with ultrapure concentrated nitric acid at $T=100{ }^{\circ} \mathrm{C}$ for $8 \mathrm{~h}$. The results showed that the treatment was effective since the recovery of $\mathrm{Fe}$ was $98 \pm 12 \%$.

Samples were measured in a 575 AA Varian atomic absorption spectrophotometer applying the method of direct flame atomization in an air-acetylene flame with background correction. All the glassware was prewashed with a mixture containing 5\% nitric acid plus 5\% hydrochloric acid, thoroughly rinsed with double-distilled water and dried. Blank values were negligible. Detection limit was $0.10 \mathrm{mg} \mathrm{Fe} / \mathrm{L}$. Values of metal concentration were expressed as micrograms of metal per gram wet tissue.

\section{Enzyme activities}

Earthworms were homogenized on ice in $100 \mathrm{mM}$ Tris buffer (pH 7.4), at 1:3 tissue:buffer ratio (w:v), using a mechanical homogenizer. The homogenates were centrifuged at $4{ }^{\circ} \mathrm{C}$ for $30 \mathrm{~min}$ at $9000 \times \mathrm{g}$. The supernatant (post-mitochondrial fraction) and the pellet from each sample were used for the determination of AChE activity. Although most authors study AChE activity in supernatants, others have shown that in many invertebrate species, AChE activity can be found both in the supernatant and in the pellet (Basack et al. 1998; Kristoff et al. 2006). To our knowledge, there is no preliminary data on $E$. andrei. Therefore, we decided to study the effects of the different treatments on AChE activity in both fractions in order to analyze whether they display differential sensitivity in this species. CES activity was only measured in the supernatants. Proteins were determined according to the method of Lowry et al. (1951), using BSA as standard.

\section{AChE activity}

AChE activity was determined according to the method of Ellman et al. (1961) using a Shimadzu UV-1603 spectrophotometer. Kinetic measurements were performed in $50 \mathrm{mM}$ Tris buffer $\mathrm{pH} 8,0.25 \mathrm{mM}$ DTNB, and $12 \mathrm{mM} \mathrm{AcSChI}$ as substrate. Activity was recorded continuously at $412 \mathrm{~nm}$ and was corrected for spontaneous hydrolysis of the substrate. The mean readings of two replicates per sample were taken for calculations using the absorption coefficient of $13.6 \mathrm{mM}^{-1} \mathrm{~cm}^{-1}$. Specific activity was expressed as nmol of acetylthiocholine hydrolyzed per min per mg protein.

\section{CES activity}

CES activity was evaluated using p-nitrophenyl butyrate as substrate (Cacciatore et al. 2013). Activity was measured, in duplicate, in $100 \mathrm{mM}$ phosphate buffer $\mathrm{pH} 8.0$ containing 5\% acetone and $1 \mathrm{mM}$ p-nitrophenyl butyrate. The activity was monitored at $400 \mathrm{~nm}$ and the specific activity was calculated using the molar extinction coefficient of p-nitrophenol $\left(18.6 \mathrm{mM}^{-1} \mathrm{~cm}^{-1}\right)$. The results were expressed as nmol of product per min per $\mathrm{mg}$ of protein.

\section{Statistical analysis}

Results were expressed as mean \pm S.D. One-way ANOVA analyses were performed and comparisons between groups were made by Tukey's test. In all cases, data were tested prior to analysis for normality (Kolmogornov-Smirnoff test) and variance homoscedasticity (Bartlett's test). The level of significance used was 0.05 . The statistical software Instat Graph Pad version 3.01 (GraphPad Software, La Jolla, CA, USA, www.graphpad.com) and R (R Foundation for Statistical Computing, Vienna, Austria; https://www.R-project.org/) were used.

\section{Results}

\section{Goethite NP characterization}

Goethite NPs exhibited an acicular shape, with a long axis length of $100.0 \pm 5.7 \mathrm{~nm}$ (Fig. 1). EDS technique confirmed their composition, which was consistent with goethite (Table 1). 


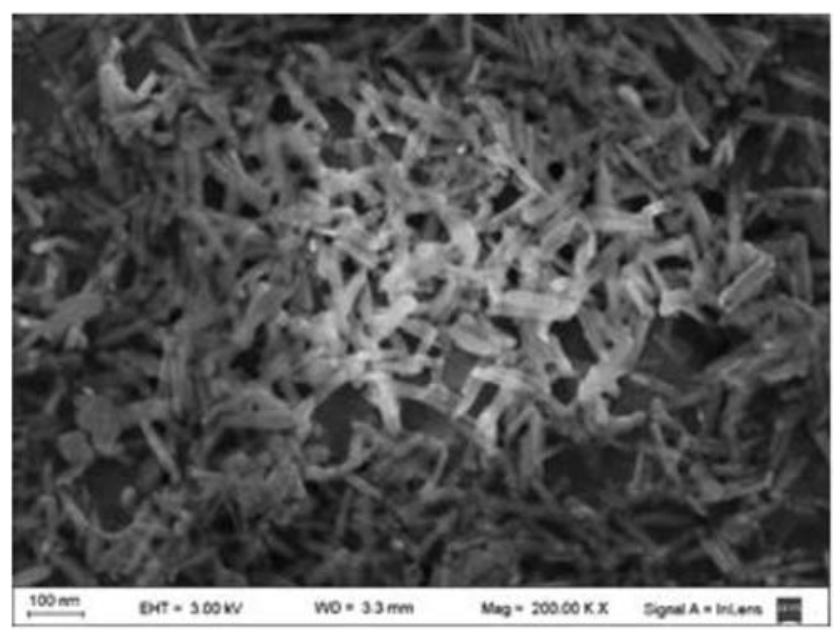

Fig. 1 SEM image of goethite nanoparticle (NPs) suspension with a magnification of $\times 200,000$

\section{Fe accumulation using the filter paper contact test}

A significant decrease in $\mathrm{Fe}$ levels was observed in organisms after single exposure to NPs and Cd, $(p<0.05)$ (Fig. 2). In contrast, no significant differences $(p>0.05)$ were observed in the Fe levels of individuals exposed either to $\mathrm{Pb}$ or to $\mathrm{CPF}$ alone, or to the mixtures of NPs+Metals. However, there was a significant increase $(65 \%, p<0.05)$ in organisms exposed to the mixture of NPs+CPF. Acetone did not affect Fe levels; thus, only control organisms exposed to distilled water are shown.

\section{Enzyme activities}

\section{Filter paper contact test}

The inhibition of AChE activity in supernatant and pellet was determined after $72 \mathrm{~h}$ of filter paper exposure to goethite NPs, $\mathrm{CPF}$, and to the mixture of NPs+CPF (Fig. 3). CPF and the binary mixture significantly inhibited $(p<0.05)$ AChE activity in both fractions. When the activity was measured in the supernatant, inhibitions of $41 \%$ and $35 \%$ were obtained for $\mathrm{CPF}$ and the binary mixture, respectively, while in the pellets, inhibitions of $29 \%$ and $36 \%$ were obtained for CPF and the binary mixture, respectively. Single exposure to goethite NPs

Table 1 Elemental analysis by EDS of goethite NPs shown in Fig. 1

\begin{tabular}{lll}
\hline Element & Weight (\%) & Atomic (\%) \\
\hline $\mathrm{C}$ & 3.32 & 7.17 \\
$\mathrm{O}$ & 41.26 & 66.86 \\
$\mathrm{Si}$ & 0.26 & 0.24 \\
$\mathrm{Fe}$ & 54.82 & 25.45 \\
$\mathrm{~S}$ & 0.34 & 0.28 \\
\hline
\end{tabular}

$E D S$, energy dispersive spectroscopy; NPs, nanoparticles did not affect the activity of AChE, in both the supernatant and pellet $(p>0.05)$.

CES activity in the supernatants followed the same trend as AChE activity (Fig. 4), since only CPF and the binary mixture of NPs+CPF significantly inhibited the activity of the enzyme (49\% and 53\% respectively).

\section{Artificial soil test}

The inhibition of AChE and CES activities was determined in the supernatants of $9000 \times g$ after 72-h and 7-day exposure to soil spiked with goethite NPs, CPF, and with the mixture of NPs+CPF (Figs. 5 and 6).

At $72 \mathrm{~h}$, only CPF caused a marked inhibition $(p<0.05)$ of $\mathrm{AChE}$ activity. No significant differences were found in earthworms single exposed to goethite NPs or to the binary mixture $(p>0.05)$ compared with control (Fig. 5). However, after 7 days, $\mathrm{CPF}$ and the mixture significantly inhibited $(p<0.05) \mathrm{AChE}$ activity. At this time point, inhibitions of $72 \%$ and $60 \%$ were obtained for $\mathrm{CPF}$ and the binary mixture, respectively, whereas goethite NPs did not inhibit AChE activity.

Neither of the treatments altered the activity of CES of earthworms exposed for $72 \mathrm{~h}(p>0.05)$ (Fig. 6). Nevertheless, after 7-day exposure, $\mathrm{CPF}$ and the mixture treatments showed significant inhibition of CES activity (59\% and $60 \%$ respectively) $(p<0.05)$, while no significant differences were found in earthworms single exposed to goethite NPs $(p>0.05)$ compared with control organisms.

\section{Discussion}

To date, few studies have investigated the co-exposure of NPs and other chemicals in soil invertebrates. The present study is, to our knowledge, the first assessment of the effects of binary mixtures of goethite NPs and $\mathrm{Cd}, \mathrm{Pb}$ or $\mathrm{CPF}$ in the earthworm E. andrei, especially on Fe uptake and modulation of $\mathrm{CPF}$ toxicity upon exposure.

\section{Fe uptake}

Terrestrial invertebrates are able to regulate, to a certain degree, the accumulation of essential metals such as $\mathrm{Cu}, \mathrm{Zn}$, and Fe (Dallinger 1993; van Gestel et al. 1993). Our results using the filter paper contact test offer some evidence for this, as single exposure for $72 \mathrm{~h}$ to goethite NPs caused a decrease in $\mathrm{Fe}$ levels. Similarly, we have previously reported decreased levels of $\mathrm{Fe}$ in $E$. andrei exposed to goethite NPs in artificial soil (Cáceres Wenzel et al. 2016). We have also reported in that previous study that during the first $48 \mathrm{~h}$ of exposure to goethite NPs using the filter paper contact test, earthworms showed increased Fe levels. Consequently, the early absorption of goethite NPs may be triggering a series of systemic 
Fig. 2 Fe levels of earthworms exposed on filter paper. The results are expressed as percentage of $\mathrm{Fe}$ compared with control and represent the mean \pm the standard deviation. Different letters indicate significant differences $(p<0.05)$. Acetone did not affect Fe levels; thus, only control organisms exposed to distilled water are shown. Control value, $54 \pm 9 \mu \mathrm{g} \mathrm{Fe} / \mathrm{g}$ tissue (wet weight). NPs, nanoparticles $\left(50 \mu \mathrm{g} / \mathrm{cm}^{2}\right)$; CPF, chlorpyrifos $\left(0.75 \mu \mathrm{g} / \mathrm{cm}^{2}\right) ; \mathrm{Cd}\left(0.40 \mu \mathrm{g} / \mathrm{cm}^{2}\right)$; $\mathrm{Pb}\left(0.74 \mu \mathrm{g} / \mathrm{cm}^{2}\right)$

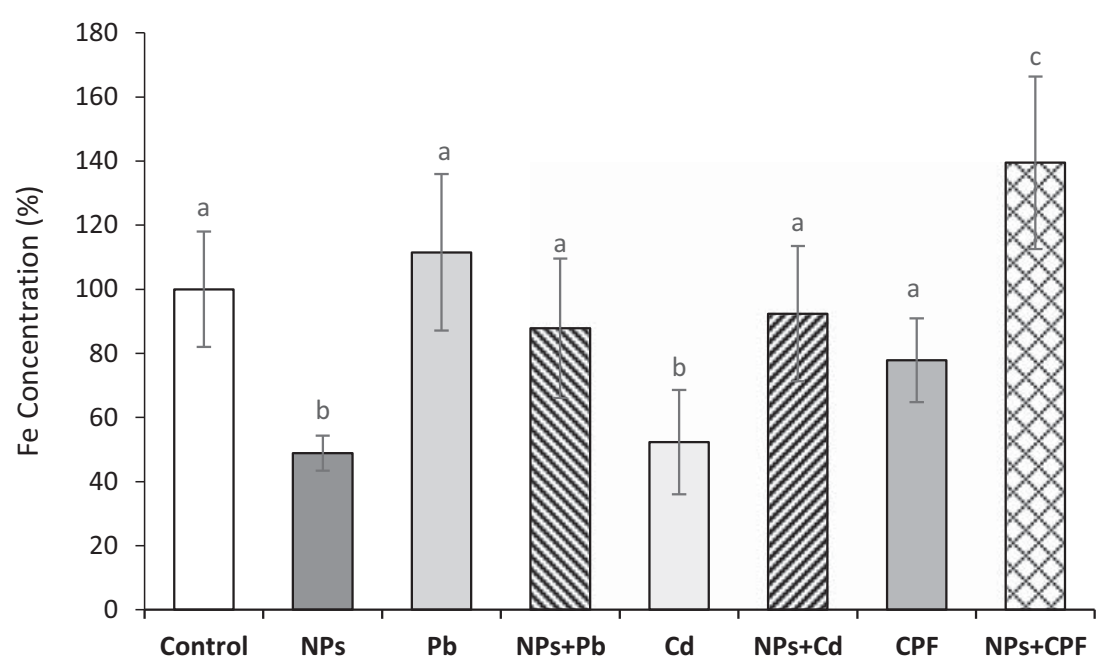

effects that would later lead to the excretion of part of the $\mathrm{Fe}$ basal levels. Coincidentally, single exposure to $\mathrm{Cd}$ seemed to trigger an analogous systemic effect. According to the literature, non-essential metals like $\mathrm{Cd}$ and $\mathrm{Pb}$ tend to accumulate mostly in the posterior section of the earthworm, particularly in the digestive tract and in the chloragogen tissue (Morgan et al. 1989). This tissue contains granules called chloragosomes. Over time, chloragogen cells increase in size, separate from the epithelium, and release the chloragosomes to the coelomic fluid, from where the latter are eliminated through the nephridia (Karaca et al. 2010). It has been postulated that chloragosomes may be essential to the endogenous ion, acid-base, and electron balance, and in this way, they are involved in the homeostatic mechanisms (Fischer and Horvith 1977). There are different types of chloragosomes. One type consists of complexes rich in phosphates that bind metals such as $\mathrm{Pb}$. A second type, named cadmosomes, contains ligands rich in thiol groups that bind $\mathrm{Cd}$, mainly low molecular weight proteins such as metallothioneins (Karaca et al. 2010). It has recently been reported that dermal exposure of $E$. fetida to $\mathrm{Cd}$ induced the dose-dependent expression of metallothionein
mRNA with a maximum induction factor of 11 , whereas in the case of those exposed to $\mathrm{Pb}$, the induction was much smaller, with a factor close to 2 (Homa et al. 2015). These differences in the behavior of $\mathrm{Cd}$ and $\mathrm{Pb}$ in the worms' tissues could be related to the differential effect of both metals on the regulation of Fe levels. However, further research is needed to confirm this hypothesis.

Unlike earthworms exposed for $72 \mathrm{~h}$ to NPs alone, those exposed to binary mixtures showed Fe levels similar (NPs+ Metals) to or higher (NPs+CPF) than controls. These results indicate that the presence of other contaminants in the exposure media can modify the uptake and/or the excretion of Fe. However, it has to be taken into account that the experiments were done using a methodology that only involves dermal contact with the chemicals (filter paper contact test). Interestingly, in a recent study performed in soil (a methodology that evaluates toxicity through two routes: by direct contact with the contaminant and by ingestion), García-Gómez et al. (2019) also reported an increase in metal concentration in earthworms exposed to mixtures of ZnO NPs and CPF compared with controls and with those exposed to ZnO NPs alone. Similarly, other
Fig. 3 AChE activity in earthworms exposed on filter paper. The activity was measured in the supernatant, and the pellet of $9000 \times g$ centrifugation. Solvent controls were performed by impregnating the filter papers with water and acetone as it is described in the "Materials and methods" section. The results represent the mean \pm the standard deviation. Different letters indicate significant differences $(p<0.05)$. NPs, nanoparticles $\left(50 \mu \mathrm{g} / \mathrm{cm}^{2}\right)$; CPF, chlorpyrifos $\left(0.75 \mu \mathrm{g} / \mathrm{cm}^{2}\right)$

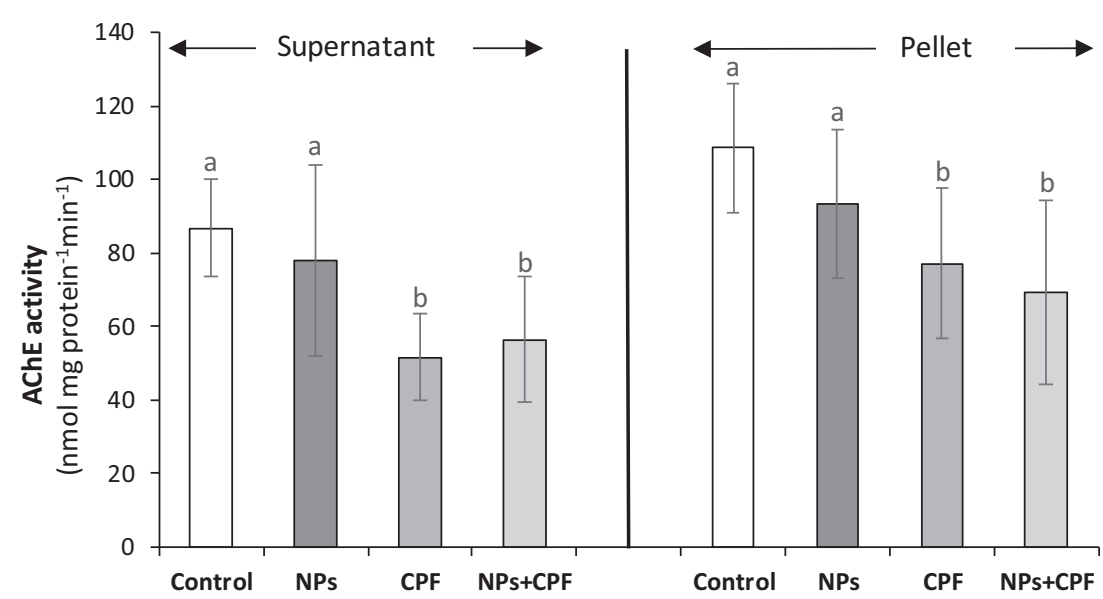


Fig. 4 CES activity in earthworms exposed on paper filter. Solvent control was performed by impregnating the filter paper with water and acetone as it is described in the "Materials and methods" section. The results represent the mean \pm the standard deviation. Different letters indicate significant differences $(p<0.05)$. NPs, nanoparticles $\left(50 \mu \mathrm{g} / \mathrm{cm}^{2}\right)$; $\mathrm{CPF}$, chlorpyrifos $\left(0.75 \mu \mathrm{g} / \mathrm{cm}^{2}\right)$

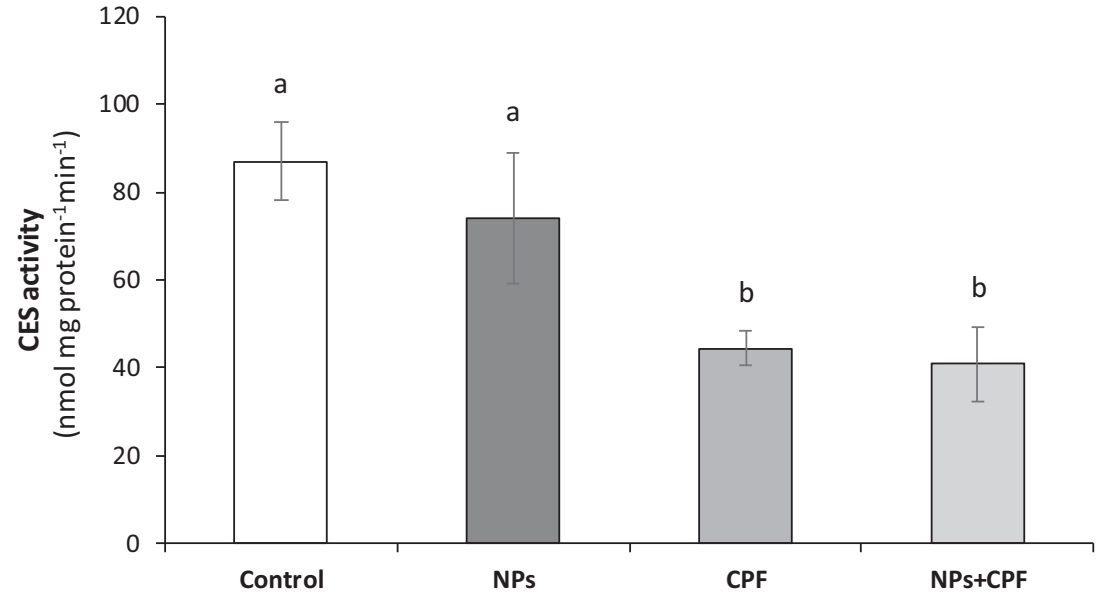

studies have shown that the presence of organic compounds increased metal accumulation in animal and plant species exposed to metallic NPs (Fang et al. 2016; Ma et al. 2017).

\section{AChE and CES activities}

Determining the inhibition of ChEs is an important sublethal endpoint in the evaluation of exposure and effect by OP and carbamate pesticides. Caselli et al. (2006) characterized the activity of these enzymes in $E$. andrei and found that they are mainly represented by AChE. There are numerous studies on the effects of OP pesticides on earthworms, and most of them are focused on the study of individual pesticides or on binary mixtures of OPs (Booth and O'Halloran 2001; Collange et al. 2010; Velki and Hackenberger 2013a, b; Stepić et al. 2013; Chen et al. 2014). On the other hand, there is little information about the effects of NPs on ChEs of soil organisms.

Earthworms exposed to CPF showed a reduction in AChE activity. This inhibition was observed in pellet-AChE as well as in supernatant-AChE, suggesting that both enzyme sources have similar sensitivity to the OP, and using both toxicity methods. AChE activity was not affected in earthworms exposed to goethite NPs in any of the experiments. Similarly, García-Gómez et al. (2019) reported that ZnO NPs did not cause significant changes in AChE activity in E. andrei exposed (28 days) in soil at exposure concentrations even higher than the one used in the present study. In contrast, other authors have reported induction of this activity in Enchytraeus albidus earthworms exposed in artificial soil to high concentrations $(750 \mathrm{mg} / \mathrm{kg}$ and $1000 \mathrm{mg} / \mathrm{kg})$ of $\mathrm{ZnO}$ NPs (Hackenberger et al. 2019).

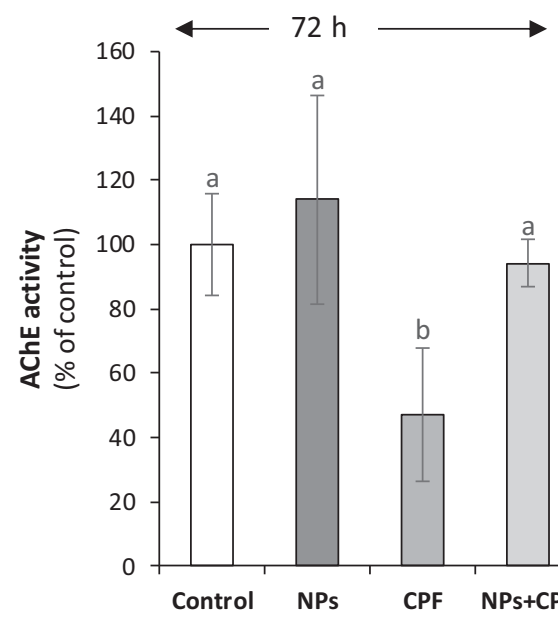

Fig. 5 AChE activity in earthworms exposed in artificial soil. Solvent control was performed by adding acetone and water as it is described in the "Materials and methods" section. The results are expressed as percentage of control and represent the mean \pm the standard deviation. Seventy-two-hour control value, $41.9 \pm 6.6 \mathrm{nmol} \mathrm{mg}$ protein $^{-1} \mathrm{~min}^{-1}$. 


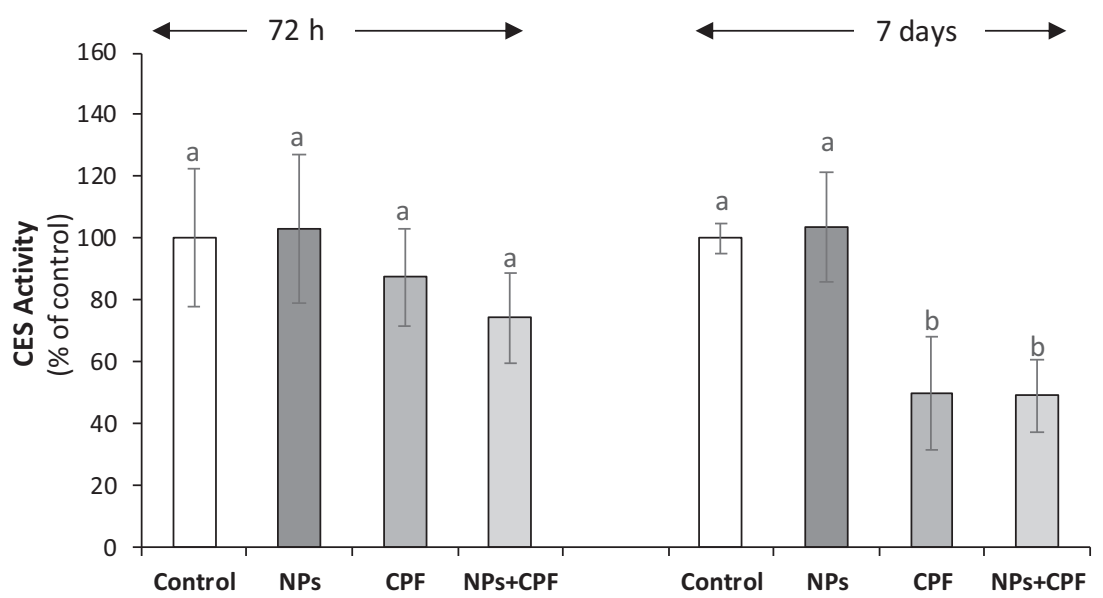

Fig. 6 CES activity in earthworms exposed in artificial soil. Solvent control was performed by adding acetone and water as it is described in the "Materials and methods" section. The results are expressed as percentage of control and represent the mean \pm the standard deviation. Seventy-two-hour control value, $61.3 \pm 13.7 \mathrm{nmol} \mathrm{mg} \mathrm{protein}{ }^{-1} \mathrm{~min}^{-1}$.
Seven-day control value, $98.1 \pm 4.9 \mathrm{nmol} \mathrm{mg}$ protein ${ }^{-1} \min ^{-1}$. Means noted with different letters within each treatment duration are significantly different $(p<0.05)$. NPs, nanoparticles $(100 \mathrm{mg} / \mathrm{kg})$; CPF, chlorpyrifos $(20 \mathrm{mg} / \mathrm{kg})$
In regard to joint effects, the co-exposure with goethite NPs diminished the effect of the OP on AChE activity at a short exposure time in artificial soil $(72 \mathrm{~h})$. However, this behavior was not observed at $72 \mathrm{~h}$ using the filter paper contact test or at 7 days using the artificial soil test. Instead, in these last two assays, exposure to the mixture of NPs+CPF induced a similar degree of inhibition than single CPF exposure. Similarly, García-Gómez et al. (2019) reported that AChE activity in E. andrei earthworms exposed (28 days) to natural soil spiked with the mixture of ZnO NPs and CPF significantly diminished compared with control, and that this inhibition was similar to the one observed in organisms single exposed to CPF.

CES comprise a group of enzymes with low substrate specificity that has been frequently reported as more sensitive to OPs than ChEs in invertebrates (Wheelock et al. 2008; Cacciatore et al. 2013). To the best of our knowledge, the effects of metal oxide NPs on E. andrei CES activity have not been studied before. Present results using both toxicity tests followed the same trend as those for AChE. Earthworms exposed to the mixture showed similar inhibition of CES activity than the earthworms exposed only to CPF. On the contrary, goethite NPs did not inhibit the activity of CES. Several isoenzymes with CES activity are present in total tissue homogenates; thus, there are different substrates to measure their activity (Sanchez-Hernandez and Wheelock 2009). Our results using p-nitrophenyl butyrate as substrate are in agreement with the observation of Oneto et al. (2005) that CES activity in earthworms measured with phenylthioacetate as substrate would be equally sensitive to OP inhibition as ChEs activity. However, this would be valid if the test is performed using the artificial soil test at exposure times not less than 7 days, or the filter paper contact test.

\section{Conclusions}

Our study shows the importance of evaluating the uptake of NPs in co-exposure studies with other contaminants. In this regard, the use of the contact filter paper test proved to be a quick and easy alternative for assessing combined effects of mixtures in earthworms.

Fe levels in the earthworms exposed only to goethite NPs were lower than basal values, suggesting systemic effects. On the contrary, earthworms exposed to binary mixtures showed $\mathrm{Fe}$ levels similar (NPs+Metals) to or higher (NPs+CPF) than controls. These differences in the pattern of $\mathrm{Fe}$ accumulation indicate that the presence of other contaminants in the exposure media can modify the uptake and/or the excretion of $\mathrm{Fe}$ and evidence the interactions that may be found in binary mixtures of metal oxide NPs and other pre-existing contaminants in the soil ecosystem.

$E$. andrei exposed to the binary mixture of $\mathrm{NPs}+\mathrm{CPF}$ showed similar inhibitions in AChE and CES activities to organisms exposed only to CPF both in the paper filter contact test and in the artificial soil test (7-day exposure). Furthermore, the enzymatic activities in the individuals exposed only to NPs were comparable with those registered in control organisms. This suggests that NPs did not produce neurotoxic effects, and that the inhibition of the enzymes' activities in all cases was due to the presence of the pesticide.

Acknowledgments The experiments using the filter paper test are part of the $\mathrm{PhD}$ thesis of MICW.

Author contributions The experiments on artificial soil were performed by JSF, MICW, and FNB; MICW, JSF, and ACC wrote the manuscript. 
Funding information This work was financially supported by grants from the University of Buenos Aires (grants 20020130100454BA, 20020170100106BA)

\section{References}

Aldridge WN (1953) Serum esterases I: two types of esterase (A and B) hydrolysing p-nitrophenyl acetate, propionate and butyrate, and a method for their determination. Biochem J 53:110-117. https://doi. org/10.1006/eesa.1997.1560

Alloway B (2013) Bioavailability of elements in soil. In: Essentials of medical geology: Revised Edition. Springer, pp 351-373

ATSDR A for TS and DR (2019) Toxicological profile for lead (draft for public comment). Atlanta, GA: U.S.

Basack SB, Oneto ML, Fuchs JS, Wood EJ, Kesten EM (1998) Esterases of Corbicula fluminea as biomarkers of exposure to organophosphorus pesticides. Bull Environ Contam Toxicol 61:569-576. https:// doi.org/10.1007/s001289900799

Booth LH, O'Halloran K (2001) A comparison of biomarker responses in the earthworm Aporrectodea caliginosa to the organophosphorus insecticides diazinon and chlorpyrifos. Environ Toxicol Chem 20: 2494-2502

Cacciatore LC, Verrengia Guerrero N, Cochón AC (2013) Cholinesterase and carboxylesterase inhibition in Planorbarius corneus exposed to binary mixtures of azinphos-methyl and chlorpyrifos. Aquat Toxicol 128-129:124-134. https://doi.org/10.1016/j.aquatox.2012.12.005

Cáceres Wenzel MI, Gigena J, Fuchs JS et al (2016) Goethite nanoparticles in Eisenia andrei: uptake, subcellular effects and their influence on the accumulation of $\mathrm{Cd}$ and $\mathrm{Pb}$. Química Viva:29-44 (in Spanish)

Caselli F, Gastaldi L, Gambi N, Fabbri E (2006) In vitro characterization of cholinesterases in the earthworm Eisenia andrei. Comp Biochem Physiol - C Toxicol Pharmacol 143:416-421. https://doi.org/10. 1016/j.cbpc.2006.04.003

Chen C, Wang Y, Zhao X, Wang Q, Qian Y (2014) Comparative and combined acute toxicity of butachlor, imidacloprid and chlorpyrifos on earthworm, Eisenia fetida. Chemosphere 100:111-115. https:// doi.org/10.1016/j.chemosphere.2013.12.023

Chernyshova IV, Ponnurangam S, Somasundaran P (2011) Effect of nanosize on catalytic properties of ferric (hydr)oxides in water: mechanistic insights. J Catal 282:25-34. https://doi.org/10.1016/j. jcat.2011.05.021

Collange B, Wheelock CE, Rault M, Mazzia C, Capowiez Y, SanchezHernandez JC (2010) Inhibition, recovery and oxime-induced reactivation of muscle esterases following chlorpyrifos exposure in the earthworm Lumbricus terrestris. Environ Pollut 158:2266-2272. https://doi.org/10.1016/j.envpol.2010.02.009

Cross KM, Lu Y, Zheng T et al (2010) Water decontamination using iron and iron oxide nanoparticles - nanotechnology applications for clean water [book]. In: Savage N, Diallo M, Duncan J, Street ASE (eds) Nanotechnology applications for clean water, New York

Dallinger R (1993) Strategies of metal detoxification in terrestrial invertebrates. Ecotoxicol Met Invertebr:245-289

Dowling AP (2004) Development of nanotechnologies. Nano Today 7 : 30-35. https://doi.org/10.1016/S1369-7021(04)00628-5

DTU Environment (2018) The nanodatabase. http://nanodb.dk/en/.

Ellman GL, Courtney KD, Andres V, Featherstone RM (1961) A new and rapid colorimetric determination of acetylcholinesterase activity. Biochem Pharmacol 7:88-95. https://doi.org/10.1016/00062952(61)90145-9

Fang Q, Shi Q, Guo Y, Hua J, Wang X, Zhou B (2016) Enhanced bioconcentration of Bisphenol $\mathrm{A}$ in the presence of nano-TiO2 can lead to adverse reproductive outcomes in zebrafish. Environ Sci Technol 50:1005-1013. https://doi.org/10.1021/acs.est.5b05024
Fischer E, Horvith I (1977) In vivo cumulation and discharge of azine, thiazine and xanthene dyes and their effects on the chloragogen cells of Lumbricidae (Oligochaeta). Acta Biol Hung 28:33-47

García-Gómez C, Babín M, García S, Almendros P, Pérez RA, Fernández MD (2019) Joint effects of zinc oxide nanoparticles and chlorpyrifos on the reproduction and cellular stress responses of the earthworm Eisenia andrei. Sci Total Environ 688:199-207. https://doi.org/10. 1016/j.scitotenv.2019.06.083

Gong P, Perkins EJ (2016) Earthworm toxicogenomics: a renewed genome-wide quest for novel biomarkers and mechanistic insights. Appl Soil Ecol 104:12-24. https://doi.org/10.1016/j.apsoil.2015.11. 005

Hjorth R, Coutris C, Nguyen NHA et al (2017) Ecotoxicity testing and environmental risk assessment of iron nanomaterials for sub-surface remediation - recommendations from the FP7 project NanoRem. Chemosphere. https://doi.org/10.1016/j.chemosphere.2017.05.060

Homa J, Rorat A, Kruk J, Cocquerelle C, Plytycz B, Vandenbulcke F (2015) Dermal exposure of Eisenia andrei earthworms: effects of heavy metals on metallothionein and phytochelatin synthase gene expressions in coelomocytes. Environ Toxicol Chem 34:13971404. https://doi.org/10.1002/etc. 2944

Hackenberger DK, Stjepanović N, Lončarić Ž, Hackenberger BK (2019) Effects of single and combined exposure to nano and bulk zincoxide and propiconazole on Enchytraeus albidus. Chemosphere 224:572-579. https://doi.org/10.1016/j.chemosphere.2019.02.189

Jänsch S, Frampton GK, Römbke J, van den Brink P, Scott-Fordsmand JJ (2006) Effects of pesticides on soil invertebrates in model ecosystem and field studies: a review and comparison with laboratory. Environ Toxicol Chem 25:2490-2501

Kaegi R, Sinnet B, Zuleeg S et al (2010) Release of silver nanoparticles from outdoor facades. Environ Pollut. https://doi.org/10.1016/j. envpol.2010.06.009

Karaca A, Kizilkaya R, Turgay OC, Cetin SC (2010) Effects of earthworms on the availability and removal of heavy metals in soil. In: Soil heavy metals. pp 369-388

Kristoff G, Guerrero NV, de D’Angelo AMP, Cochón AC (2006) Inhibition of cholinesterase activity by azinphos-methyl in two freshwater invertebrates: Biomphalaria glabrata and Lumbriculus variegatus. Toxicology 222:185-194. https://doi.org/10.1016/j.tox. 2006.02.018

Lowe CN, Butt KR (2007) Earthworm culture, maintenance and species selection in chronic ecotoxicological studies: a critical review. Eur J Soil Biol 43. https://doi.org/10.1016/j.ejsobi.2007.08.028

Lowry OH, Rosebrough NJ, Lewis Farr A, Randall RJ (1951) Protein measurement with the fenol phenol reagent. Readings 193:265-275

Ma C, Liu H, Chen G, et al (2017) Effects of titanium oxide nanoparticles on tetracycline accumulation and toxicity in: Oryza sativa (L.)

Missaoui WN, Arnold RD, Cummings BS (2018) Toxicological status of nanoparticles: what we know and what we don't know. Chem Biol Interact November 1:1-12. https://doi.org/10.1016/j.cbi.2018.07. 015

Morgan JE, Norey CG, Morgan AJ, Kay J (1989) A comparison of the cadmium-binding proteins isolated from the posterior alimentary canal of the earthworms Dendrodrilus rubidus and Lumbriculus rubellus. Comp Biochem Physiol Part C, Comp 92:15-21. https:// doi.org/10.1016/0742-8413(89)90195-3

Nanorem (2017) NanoRem pilot site-Spolchemie II, Czech Republic: remediation of BTEX compounds using nano-goethite. NanoRem Bull 8:8-13

OECD (1984) "OECD 207 -earthworm, acute toxicity tests." OECD Guidel Test Chem 207:9

Oneto ML, Basack SB, Casabé NB et al (2005) Biological responses in the freshwater bivalve Corbicula fluminea and the earthworm Eisenia fetida exposed to fenitrothion. Fresenius Environ Bull 14: 716-720 
Pachapur VL, Dalila Larios A, Cledón M, Brar SK, Verma M, Surampalli RY (2016) Behavior and characterization of titanium dioxide and silver nanoparticles in soils. Sci Total Environ 563-564:933-943. https://doi.org/10.1016/j.scitotenv.2015.11.090

Parveen S, Misra R, Sahoo SK (2012) Nanoparticles: a boon to drug delivery, therapeutics, diagnostics and imaging. Nanomedicine Nanotechnology, Biol Med 8:147-166. https://doi.org/10.1016/j. nano.2011.05.016

Roberts TL (2014) Cadmium and phosphorous fertilizers: the issues and the science. Procedia Eng 83:52-59. https://doi.org/10.1016/j. proeng.2014.09.012

Sanchez-Hernandez JC, Wheelock CE (2009) Tissue distribution, isozyme abundance and sensitivity to chlorpyrifos-oxon of carboxylesterases in the earthworm Lumbricus terrestris. Environ Pollut 157:264-272. https://doi.org/10.1016/j.envpol.2008.06.041

Sanvicens N, Marco MP (2008) Multifunctional nanoparticles - properties and prospects for their use in human medicine. Trends Biotechnol 26:425-433. https://doi.org/10.1016/j.tibtech.2008.04. 005

Stepić S, Hackenberger BK, Velki M, Lončarić Ž, Hackenberger DK (2013) Effects of individual and binary-combined commercial insecticides endosulfan, temephos, malathion and pirimiphos-methyl on biomarker responses in earthworm Eisenia andrei. Environ Toxicol Pharmacol 36:715-723. https://doi.org/10.1016/J.ETAP. 2013.06.011

van Gestel CAM, Dirven-van Breemen EM, Baerselman R (1993) Accumulation and elimination of cadmium, chromium and zinc and effects on growth and reproduction in Eisenia andrei (Oligochaeta, Annelida). Sci Total Environ 134:585-597. https:// doi.org/10.1016/S0048-9697(05)80061-0

Velki M, Hackenberger BK (2013a) Inhibition and recovery of molecular biomarkers of earthworm Eisenia andrei after exposure to organophosphate dimethoate. Soil Biol Biochem 57:100-108. https://doi. org/10.1016/j.soilbio.2012.09.018
Velki M, Hackenberger BK (2013b) Different sensitivities of biomarker responses in two epigeic earthworm species after exposure to pyrethroid and organophosphate insecticides. Arch Environ Contam Toxicol 65:498-509. https://doi.org/10.1007/s00244-013-9930-4

Vijver MG, Vink JPM, Miermans CJH, Van Gestel CAM (2003) Oral sealing using glue: a new method to distinguish between intestinal and dermal uptake of metals in earthworms. Soil Biol Biochem 35: 125-132. https://doi.org/10.1016/S0038-0717(02)00245-6

Wang Y, Chen C, Qian Y, Zhao X, Wang Q, Kong X (2015) Toxicity of mixtures of $\lambda$-cyhalothrin, imidacloprid and cadmium on the earthworm Eisenia fetida by combination index ( CI ) -isobologram method. Ecotoxicol Environ Saf 111:242-247. https://doi.org/10. 1016/j.ecoenv.2014.10.015

Wheelock CE, Shan G, Ottea J (2005) Overview of carboxylesterases and their role in the metabolism of insecticides. J Pestic Sci 30:75-83. https://doi.org/10.1584/jpestics.30.75

Wheelock CE, Phillips BM, Anderson BS, Miller JL, Miller MJ, Hammock BD (2008) Applications of carboxylesterase activity in environmental monitoring and toxicity identification evaluations (TIEs). Rev Environ Contam Toxicol 195:117-178. https://doi.org/ 10.1007/978-0-387-77030-7 5

Wu X, Cobbina SJ, Mao G, Xu H, Zhang Z, Yang L (2016) A review of toxicity and mechanisms of individual and mixtures of heavy metals in the environment. Environ Sci Pollut Res 23:8244-8259. https:// doi.org/10.1007/s11356-016-6333-x

Wu Y, Pang H, Liu Y, Wang X, Yu S, Fu D, Chen J, Wang X (2019) Environmental remediation of heavy metal ions by novelnanomaterials: a review. Environ Pollut 246:608-620. https://doi. org/10.1016/j.envpol.2018.12.076

Publisher's note Springer Nature remains neutral with regard to jurisdictional claims in published maps and institutional affiliations. 